\title{
Numerical investigation on the thermo-mechanical behavior of a quadratic cross section pile heat exchanger
}

\author{
Maria Alberdi-Pagola, Søren Madsen, Rasmus Lund Jensen, Søren Erbs Poulsen
}

\begin{abstract}
Pile heat exchangers are traditional foundation piles with built in heat exchangers. As such, the footing of the building both serves as a structural component and a heating/cooling supply element. The existing geotechnical design standards do not consider the nature of thermo-active foundations and, therefore, there is a need to develop guidelines to design them properly. This paper contributes by studying the thermo-mechanical behavior of the precast piles which are 15-meter long and have a quadratic cross section and a W-shape pipe heat exchanger. This article aims to numerically assess the additional changes in the pile load transfer generated by its heating and cooling. In addressing this objective, a preliminary multi-physical finite element analysis is conducted which serves as a tool for exploring: i) the thermally induced mechanical stresses within the concrete and on the pile-soil axial and shaft resistances; ii) the maximum upward/downward displacements. A one-year time span is considered under operational and extreme thermal boundary conditions. The results show that a typical geothermal utilization of the energy foundation does not generate significant structural implications on the geotechnical capacity of a single energy pile. However, ground thermal loads need to be considered in the design phase to account for potential extreme temperature changes, which could generate thermal stresses that equalize the mechanically generated ones.
\end{abstract}

\section{INTRODUCTION}

The Danish government aims to reduce 40\% the greenhouse gas emissions by 2020 relative to 1990 and to cover the total domestic energy requirements by renewable resources by 2050 (Danish Energy Agency, 2012). In this matter, ground source heat pump systems cooperate in the transition towards sustainable energy sources.

Pile heat exchangers, also known as energy piles, are thermo-active ground structures that utilize reinforced concrete foundation piles as vertical closed-loop heat exchangers, developed as an alternative to borehole heat exchangers (Brandl, 2006). As such, the foundation of the building both serves as a structural and a heating and/or cooling component and as a result, their dimensioning becomes a coupled thermo-hydro-mechanical challenge. Pile heat exchangers can vary in length from 10 to 50 meters and in width from 0.3 to 1.5 meters. Besides, the geothermal pipes can be placed in the central part or closer to the pile edge (Brandl, 2006). Due to this variety, several experimental and numerical studies attempt to develop novel approaches that 
characterize the heat transfer in and around such structures (Cecinato and Loveridge, 2015, Park et al., 2013, Loveridge and Powrie, 2013, Bandos et al., 2014).

Pile design approaches in Europe are based on the determination of the ultimate and serviceability limit states according to Eurocode 7 (DS/EN 1997-1/AC, 2010). Yet the regulations do not consider the geothermal use in the foundation design process with regards to structural requirements. Thermal piles can be subject to a net change of the temperature relative to the initial condition over time, which causes thermal stresses and head displacements. Under thermo-elastic conditions, if the pile is a free body, i.e. it has no restraints, it will expand while heating and contract during cooling to yield a thermal free strain. In reality, a pile will not expand or contract freely as it will be confined by the structure on top and the surrounding soil, at different levels of degrees of freedom (Figure 1). As a result, the measured strain change due to temperature changes will be less than the free axial thermal strain and the constrained strains will develop thermal stresses (GSHP Association, 2012).

a)

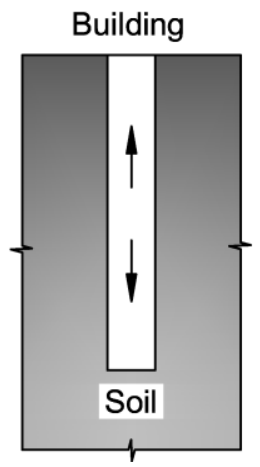

b)

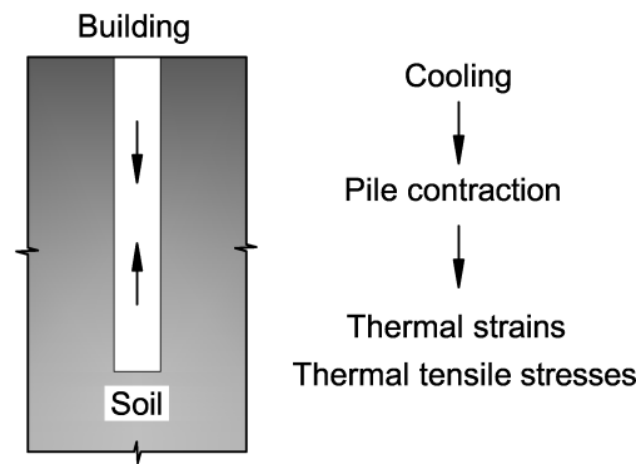

Figure 1 Response mechanism of a pile heat exchanger to thermal loading, a) for heating and b) for cooling.

The structural implications of the thermal loading in the service life of energy piles is still uncertain (Pahud and Hubbuch, 2007). The study of the effect of the mechanical loads in the long term is still an issue for practitioners and, therefore, energy foundations carry the same difficulties exacerbated by the cyclic (seasonal) thermal load effects in the soil and pile-soil interface. It has not been investigated whether the long-term bearing capacity of thermo-active piles is affected by the thermal cycles even though no operational failures have been reported to date. To ensure that the geotechnical performance of the pile is not negatively affected, conservative safety procedures are applied: the fluid temperature in the ground loop is not allowed to go below $2{ }^{\circ} \mathrm{C}$ and there is a tendency to place more energy piles than required (VDI, 2001, VDI, 2010, SIA, 2005, NHBC Foundation, 2010, GSHP Association, 2012, Loveridge, 2012, Mimouni and Laloui, 2014).

The temperature range imposed by the geothermal exploitation of the foundations falls between $2{ }^{\circ} \mathrm{C}$ to $30^{\circ} \mathrm{C}$ or higher and their nature depends on the needs of the building (Laloui and Di Donna, 2013). These temperature changes can affect the stress state at the pile-soil interface and the shear strength of the soil that affects the tip resistance (Olgun et al., 2014). Recent studies on the impact of thermal loading at pile-soil interface indicate that the bearing capacity of the pile is not significantly affected (Suguang et al., 2014, Di Donna, 2014, GSHP Association, 2012, Mimouni, 2014, Olgun et al., 2014). Xiao et al. (2014) and Di Donna (2014) have analyzed monotonic temperature variations in the range from $6^{\circ} \mathrm{C}$ to $50^{\circ} \mathrm{C}-60^{\circ} \mathrm{C}$ and have concluded that higher temperatures increase the strength of the clay-concrete contact and that the sand-concrete interface is not affected by the monotonic temperature changes. 
Two main full-scale performance studies of energy piles lead the state of the art in the field: the Lambeth College, London (Bourne-Webb et al., 2009) and the École Polytechnique Fédérale de Lausanne EPFL (Laloui et al., 2006, Mimouni, 2014). Both studies conclude: 1) short-term plastic response of soils has not been observed due to the geothermal use since effective stresses typically are within yield surfaces, i.e., within the thermo-elastic domain; 2) the additional stresses produced in the energy pile due to thermal loads depend on the degrees of freedom of the pile. Therefore, the pile-soil interaction under working mechanical and thermal loads provokes systems that depend on soil conditions, level of pile confinement and magnitude of thermal loads, making hard to establish general rules. Fortunately, simple descriptive mechanistic frameworks have been established from observed behaviors (BourneWebb et al., 2009, Amatya et al., 2012, Knellwolf et al., 2011, Laloui and Di Donna, 2011).

Numerical tools are used to analyze not just experimental conditions but also potential scenarios, supporting the understanding of the physics behind the problem and assisting the development of behavior rules. Several numerical studies explore the thermo-mechanical phenomena of energy piles in different soil conditions. Regarding load transfer mechanisms, Suryatriyastuti et al. (2012), Hassani Nezhad Gashti et al. (2014)and Laloui et al. (2006) encompass good examples validated against experimental data.

The understanding of the behavior of the thermo-active foundations is still fundamental for their optimization during the design phase and under operational conditions. This paper presents a preliminary attempt to describe the thermo-mechanical implications, additional to those due to static axial loading, disturbing the thermally active version of a single precast quadratic cross section pile under operational and extreme situations for a specific case study, described in Alberdi-Pagola et al. (2016).

This paper is organized as follows: firstly, three ground thermal demand scenarios are defined based on measured data. Secondly, a three dimensional finite element model is described where the thermal loads are used as boundary conditions. Then, the Results and Discussion section analyzes the structural implications under the different thermal circumstances on a 1-year time span and, finally, conclusions are drawn.

\section{ANALYZED DATA}

The equivalent energy wave technique has been developed by Abdelaziz et al. (2015) to analyze the long-term performance of ground coupled heat exchangers. It generates a realistic annual sine curve based on measured operational ground thermal loads. The ground load is defined as the power measured through the ground loop of the ground source heat pump installation, divided by the number of energy piles and the length of the piles [W/m].
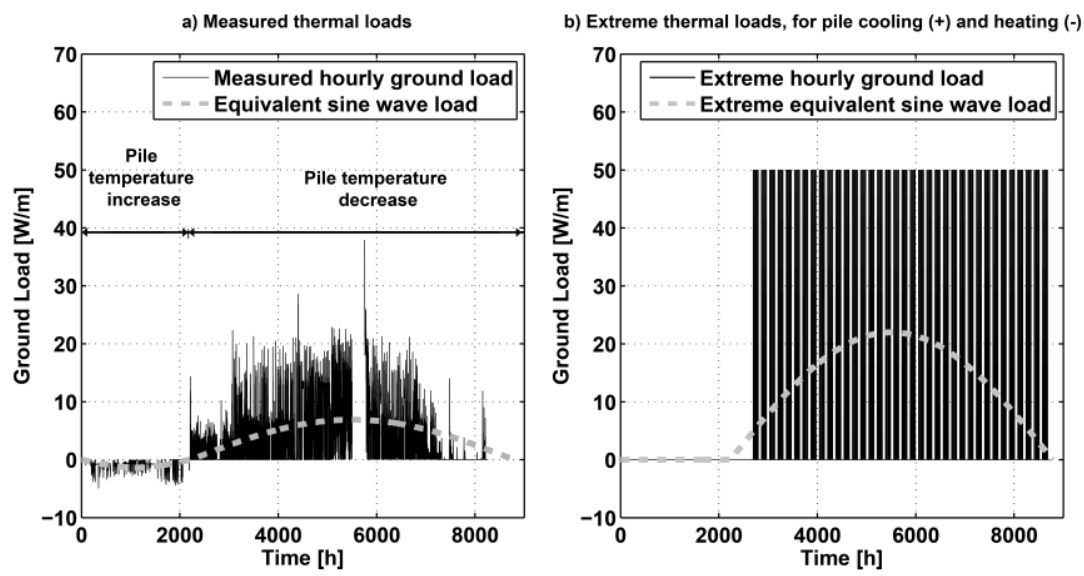

Figure 2 a) Measured ground thermal load and its equivalent wave; b) Generated ground thermal load and its equivalent wave, valid for extreme cooling of the pile (when heat extraction) and extreme heating of the pile (when heat injection). 
An equivalent wave has been generated for a year of operational data available from Rosborg Gymnasium reported in Alberdi-Pagola et al. (2016) (Figure 2a). The treated ground source heat pump installation is mainly used for heating yet some free-cooling partially recharges the ground in summer (Figure 2a). This situation imitates the current working conditions and it will be referred as "Measured thermal loads". Two more scenarios account for extreme thermal load conditions (Figure 2b), making the heat pump work in peak capacity conditions during 8 hours per day, 5 days a week. The extreme heat extraction from the ground represents an extreme heating need of the building during winter with no recharge in summer. The extreme heat injection to the ground mimics an extreme cooling need of the building. The extreme cases equal in magnitude but own opposite sign.

\section{METHODOLOGY}

Three dimensional finite element modelling has been used to analyze the coupled thermo-mechanical problem of a single quadratic cross section thermal pile. The model aims to reflect the geotechnical and operational conditions at the mentioned case study.

\section{Finite element model characteristics}

The finite element software COMSOL Multiphysics 5.2 (COMSOL Multiphysics, 2015) has been used to calculate the subsurface temperature response and the stress and strain domains in and near the pile heat exchanger under heating and cooling loads. A linear-elastic behavior was imposed to all the model domain, based on the observed thermo-elastic structural behavior of an energy pile under normal working in-situ conditions reported in Bourne-Webb et al. (2009) and Laloui et al. (2006). The thermal interaction of the pile heat exchanger with the surrounding soil is modelled by pure conduction. The presence of groundwater flow is ignored in the calculations. The soil is assumed to be isotropic and homogeneous.
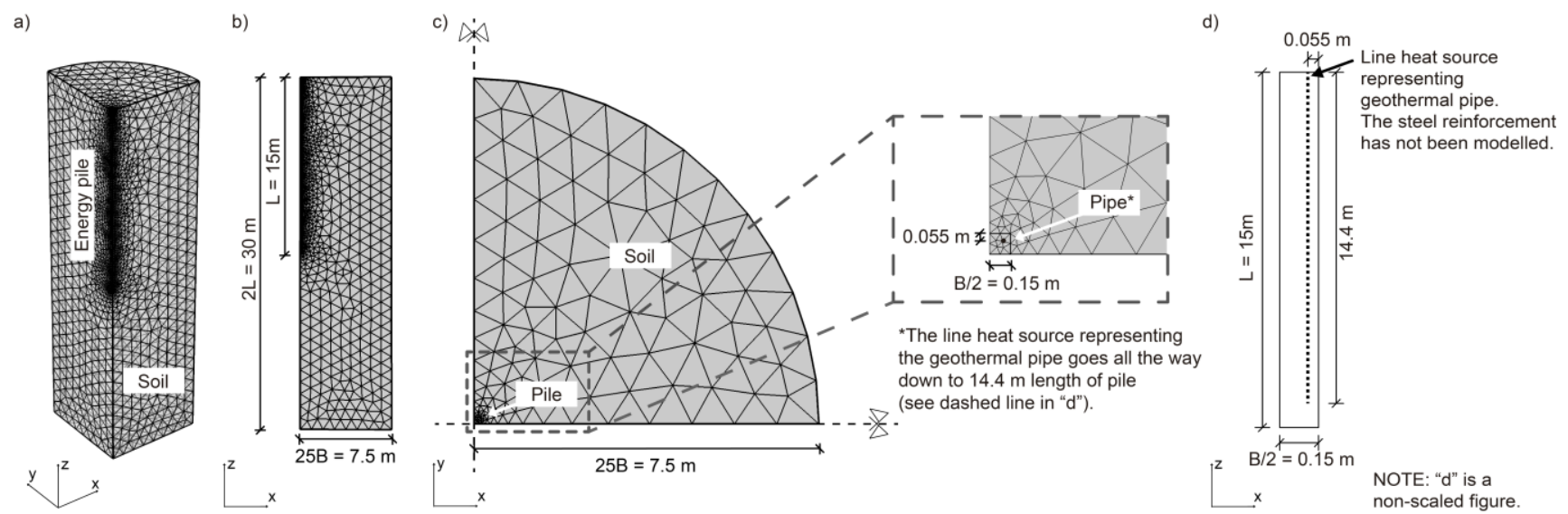

Figure 3 a) Illustration of the $3 \mathrm{D}$ finite element mesh, b) side view of the finite element model c) top view of the finite element model and zoomed detail of the position of the simplified geothermal pipe d) Non-scaled side view of the pile heat exchanger and the simplified geothermal pipe.

The 3D model contains two domains (Figure 3a): the soil and the concrete pile, which contains a line heat source mimicking the PE-X pipe (Figure 3c). The model dimensions were established following the suggestions by Suryatriyastuti et al. (2012): lateral extension 25B, being $B=0.3 \mathrm{~m}$ (pile side), and vertical height for the soil volume 
2L, being $\mathrm{L}=15 \mathrm{~m}$ (pile length). A quarter of the domain has been simulated taking advantage of symmetries (Figure 3b). No interface elements between the pile and the soil have been considered, allowing a perfect contact between them. This has been considered a conservative scenario since Suryatriyastuti et al. (2012) and Hassani Nezhad Gashti et al. (2014) reported that simulated thermal stresses are larger in perfect contact. The finite element model uses a mesh with 34,505 tetrahedral elements, more refined around the pile and it gets coarser with distance (Figure 3a).

\section{Material properties}

Table 1 summarizes the parameters for the pile and the soil (sand) used in the model. These values are taken from performed measurements and literature. The steel reinforcement has not been considered as it means less than $5 \%$ of the total weight of the pile.

Table 1. Properties of the materials used in the model.

\begin{tabular}{lc}
\hline \multicolumn{1}{c}{ Parameter } & Value \\
\hline \hline Young modulus pile & $41,900.00 \mathrm{MPa}$ \\
Young modulus rigid sand (Geotechdata.info, 2013) & $30.00 \mathrm{MPa}^{*}$ \\
Poisson ratio pile & 0.30 \\
Poisson ratio soil & 0.30 \\
Thermal expansion coefficient pile & $3.00 \mathrm{E}-051 / \mathrm{K}$ \\
Thermal expansion coefficient soil & $1.50 \mathrm{E}-051 / \mathrm{K}$ \\
Density concrete & $2370.00 \mathrm{~kg} / \mathrm{m}^{3}$ \\
Density soil & $1900.00 \mathrm{~kg} / \mathrm{m}^{3}$ \\
Thermal conductivity concrete & $1.80 \mathrm{~W} / \mathrm{m}^{3} / \mathrm{K}$ \\
Thermal conductivity soil & $2.30 \mathrm{~W} / \mathrm{m} / \mathrm{K}$ \\
Volumetric heat capacity concrete & $1.98 \mathrm{MJ} / \mathrm{m}^{3} / \mathrm{K}$ \\
Volumetric heat capacity soil & $2.60 \mathrm{MJ} / \mathrm{m}^{3} / \mathrm{K}$ \\
\hline$*$ Considered constant with depth. &
\end{tabular}

\section{Initial- and boundary conditions}

Rolled displacement boundary conditions fix the horizontal movement on the side borders while pinned conditions restrict both the horizontal and vertical movement on the bottom boundary of the soil domain. To account for the gravity effect and the mechanical load, a two-step stationary run has been performed. These steps provoke stresses and strains, both in the concrete and in the soil that should be added to the thermally-induced ones. The initial soil vertical effective stress is $0.25 \mathrm{MPa}$ at the bottom of the pile and the horizontal stresses of the soil are neglected for the hereon analysis. The bearing capacity of the 15 meter pile is $1510 \mathrm{kN}$ in compression (non factored), estimated from data from Dansk Geoteknik A/S (1973). The pile head displacement under geostatic conditions, meaning no mechanical load added, is $16 \mathrm{~mm}(1.1 \mathrm{~mm} / \mathrm{m}$ of pile length).

The pile is restrained at the toe allowing the free movement during pile cooling and prohibiting the expansion while heating, mimicking an end-bearing pile. The mechanical load applied at the top of the pile is $600 \mathrm{kN}$ (factoring the bearing capacity 2.5 times), which gives a ratio of 0.1 between the applied load and the compressive strength of concrete $(68 \mathrm{MPa})$. The application of this load resulted in a pile top settlement of $1 \mathrm{~mm}(0.06 \mathrm{~mm} / \mathrm{m}$ of pile length).

Regarding the thermal boundary conditions, an initial temperature of $10^{\circ} \mathrm{C}$, similar to the observed average undisturbed ground temperature at the represented case, is assumed in the whole domain. A constant temperature boundary of $10^{\circ} \mathrm{C}$ is also applied to the ground level and the side boundaries of the soil block are selected as open boundaries to mimic the infinite soil (Hassani Nezhad Gashti et al., 2014).

The fluid circulating inside the pipes has been represented as a line heat source (Figure 3c) subjected to a 
transient and uniform heat rate $[\mathrm{W} / \mathrm{m}]$ over its length (described in section "Analyzed data"). There was no external mechanical load applied during the transient models to ease the estimation of the uncoupled thermal stresses and strains.

\section{RESULTS AND DISCUSSION}

The pile-soil system has been modelled, subjected to transient thermal loads over a year. The time span is limited to the available data. The analysis aims to quantify the maximum thermal stresses and the maximum thermal displacements generated in the pile-soil system due to the geothermal use. Therefore, two types of mechanical boundary conditions have been applied to the pile extremes, as described in Table 2. Besides, the provided naming code will assist the identification of each simulated case in the analysis hereby.

Table 2. Applied boundary conditions and identification of simulations.

\begin{tabular}{ccc}
\hline & Maximum thermal stresses & $\begin{array}{c}\text { Maximum thermal } \\
\text { displacements at pile head }\end{array}$ \\
\hline Boundary conditions & $\begin{array}{c}\text { Rigid connection at head and end- } \\
\text { bearing condition at toe. }\end{array}$ & $\begin{array}{c}\text { Free head movement and } \\
\text { restrained toe. }\end{array}$ \\
\hline Measured thermal loads & $1 \mathrm{~A}$ & $1 \mathrm{~B}$ \\
Extreme heat extraction & $2 \mathrm{~A}$ & $2 \mathrm{~B}$ \\
Extreme heat injection & $3 \mathrm{~A}$ & $3 \mathrm{~B}$ \\
\hline
\end{tabular}

The axial thermal stresses generated in the center of the pile for the three scenarios are shown in Figure 4a, uncoupled from the stresses generated by the mechanical load. Table 3 summarizes the main results of the transient simulations. The contour of the profiles in Figure 4 are comparable to previous literature (Hassani Nezhad Gashti et al., 2014), with a stabilized zone along the middle and two transient zones at the extremes indicating the uniform nature of the thermal effects.

For heat injection cases (simulations $1 \mathrm{~A}$ in summer and $3 \mathrm{~A}$ ), the upper zones with higher compression stresses, occur due to the influence of the constant temperature boundary condition imposed at the soil surface and the restrained movement of the pile head. The second region at the bottom might be influenced by the thermal gradients generated below the end of the heat line source and the restrained toe movement. The maximum compression stress as a result of the thermal loads reaches $6.5 \mathrm{MPa}$ (simulation 3A, Table 3). For this case, the magnitude of the temperature-induced load is very close to the purely mechanical load, increasing the solicitation of the toe, resulting on a combined load of $1185 \mathrm{kN}$, almost $80 \%$ of the pile capacity, corresponding to failure. This would not be allowed for design, as it is above the design bearing capacity (including safety factors) and it indicates that thermal loads need to be considered in the design of the energy foundations. For operational circumstances, on the other hand, the combined load in summer hardly increases $2 \%$.

A temperature increment of $1{ }^{\circ} \mathrm{C}$ results in an additional temperature-induced vertical force of $100 \mathrm{kN}$ approximately, very similar to the values reported by Laloui et al. (2006) and Amatya et al. (2012). However, in terms of stresses, the studied pile suffers considerable increases, in the order of $1000 \mathrm{kPa} /{ }^{\circ} \mathrm{C}$, due to the small cross section of the pile.

The cooling of the pile provokes a constrained contraction, generating a maximum tensile stress of $-2.2 \mathrm{MPa}$ and $-0.7 \mathrm{MPa}$ for simulations $2 \mathrm{~A}$ and $1 \mathrm{~A}$ in winter, respectively (Figure $4 \mathrm{a}$ ). The tensile stresses dissipate with depth as the upwards movement of the pile toe is permitted.

Regarding the mechanical properties of concrete, the maximum compressive stresses developed means $10 \%$ 
of the ultimate compression strength. Hence, the combined thermal and mechanical load would reach $20 \%$ of the compression resistance. The tensile strength of the concrete, without reinforcement, has been estimated as $5 \mathrm{MPa}$ from Neville (1995). It is still twice higher than the computed maximum tensile stress.

The maximum shaft shear stress estimated is $160 \mathrm{kPa}$ at the pile toe for the extreme heat injection case (simulation 3A) even though over the pile length the shear stresses were negligible. The constrained pile expansion at the pile toe induce an increase of shear stresses concentrated in the bottom region of the pile (Figure $4 \mathrm{~b}$ ). On the other hand, during pile cooling, the perfect contact in the interface increases the shaft stress component, creating a higher mobilized shear stress over the pile length for the extreme heat extraction (simulation 2A). As highlighted by Hassani Nezhad Gashti et al. (2014), the mobilization of the shaft loads when the bottom movement is allowed rises concern on the behavior of floating thermal piles.

a)

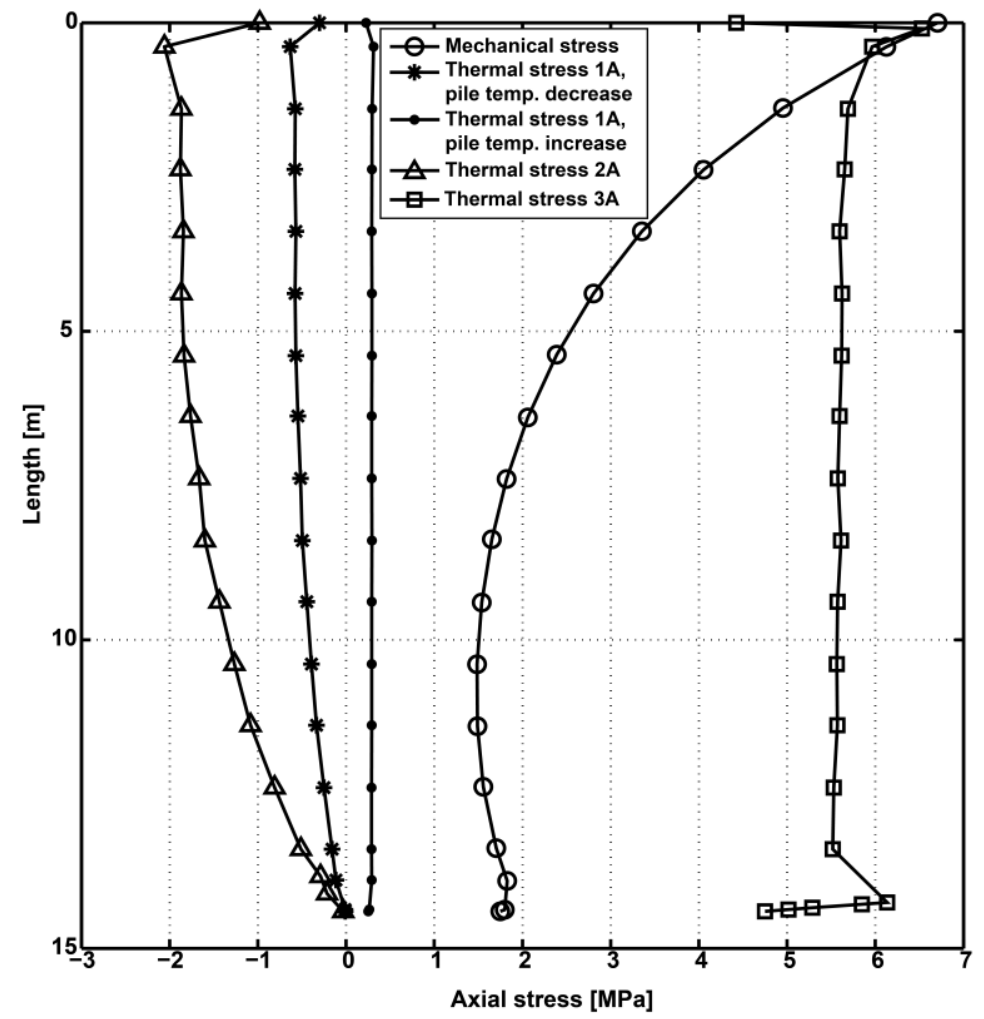

b)

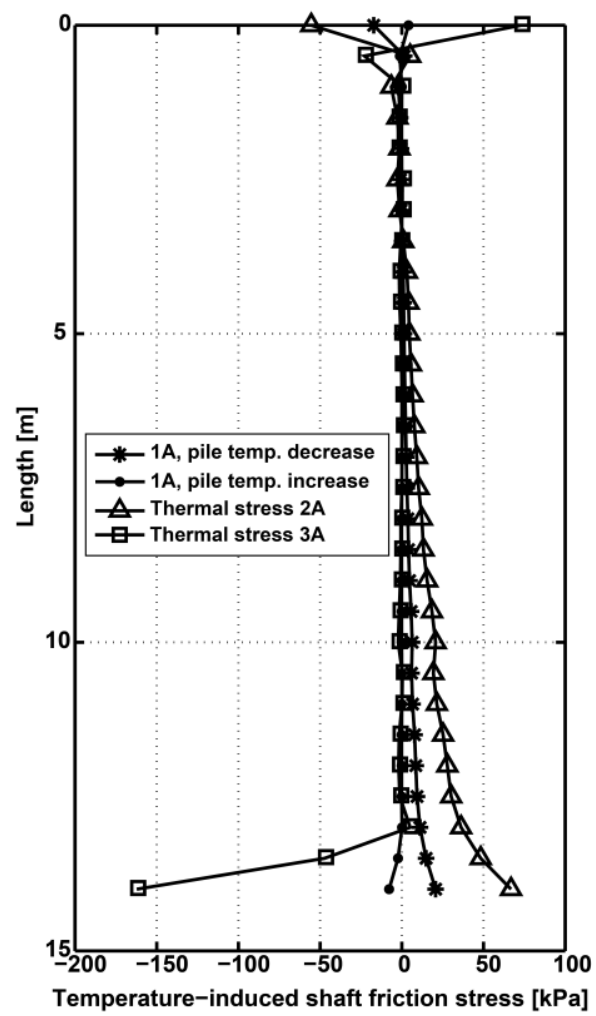

Figure 4 a) Thermally induced axial stresses over the pile length at the its center and the axial stresses mobilized by the static mechanical load. Negative sign states for tensile stresses. b) Mobilized thermally-induced shear stresses.

According to DS/EN 1997-1/AC (2010), the pile fails when it settles 10\% of the pile base diameter (i.e., $0.023 \mathrm{~mm} / \mathrm{m}$ ). For the considered cases, the displacements are insignificant (Table 3). The maximum predicted deformation belongs to the combined effects of a temperature decrease that generates the pile contraction (simulation 2B) and the mechanical load, providing a head settlement of $0.17 \mathrm{~mm} / \mathrm{m}$, i.e., $7.5 \%$ of the allowed settlement. This agrees with the conclusions from Xiao et al. (2016) who reported that the cooling cycle can dominate the serviceability limit state design of pile heat exchangers. It is concluded that the deformations resulted from the geothermal exploitation are very low, probably due to the high rigidity of the pile. 
Table 3. Maximum thermal stresses and displacements predicted for a one-year study.

Maximum temperature

change from initial condition
Maximum thermalinduced axial stress
Maximum thermal-induced

displacement of pile head relative to pile length

\begin{tabular}{cccc}
\hline \hline Measured thermal loads & & & \\
Heat injection in summer & $0.5^{\circ} \mathrm{C}$ & $0.3 \mathrm{MPa}[1 \mathrm{~A}]$ & $-0.01 \mathrm{~mm} / \mathrm{m}[1 \mathrm{~B}]$ \\
Heat extraction in winter & $2.0^{\circ} \mathrm{C}$ & $-0.7 \mathrm{MPa}[1 \mathrm{~A}]$ & $0.03 \mathrm{~mm} / \mathrm{m}[1 \mathrm{~B}]$ \\
\hline Extreme heat extraction & $-6.0^{\circ} \mathrm{C}$ & $-2.2 \mathrm{MPa}[2 \mathrm{~A}]$ & $0.11 \mathrm{~mm} / \mathrm{m}[2 \mathrm{~B}]$ \\
\hline Extreme heat injection & $6.0^{\circ} \mathrm{C}$ & $6.5 \mathrm{MPa}[3 \mathrm{~A}]$ & $-0.11 \mathrm{~mm} / \mathrm{m}[3 \mathrm{~B}]$ \\
\hline
\end{tabular}

Sign criteria: for displacements, positive means downwards and for stresses, positive means compression.

This paper investigates the additional thermal stresses and displacements generated in a pile heat exchanger due to its geothermal use over a year. The time span was limited by the available data. This rough study indicates i) orders of magnitude of the thermally induced stresses and displacements and potential temperature changes under certain thermal conditions and ii) relevant aspects that require more refining in coming studies.

The analyzed thermal loads do not produce the thermal quasi steady state situation required to dimension the long-term performance of the ground source heat pump installations. This condition would allow to quantify the total temperature change that the pile-soil system would be subjected to in the long term. Therefore, the present study underestimates the net temperature change. I.e., for heat extraction cases, higher tensile stresses and higher pile head settlements than the simulated ones would be predicted in the long term, while compression stresses would increase when heat injection is required. On the other hand, the mechanically restrained toe and head boundary conditions and the perfect contact between pile and soil are conservative measures that give rise to overestimated stress states.

\section{CONCLUSIONS}

This paper presents a preliminary approach to quantify the additional thermal stresses and displacements generated in a pile heat exchanger due to its geothermal use. For that, measured and extreme thermal loads have been applied to a linear thermo-elastic 3D finite element model of a single precast energy pile and the surrounding soil.

Transient simulations over a year show that a typical utilization of the energy foundation does not generate significant structural implications on a single thermal pile in terms of axial and mobilized shaft stresses and generated displacements. However, for extreme heating conditions, meaning a temperature increase of $6^{\circ} \mathrm{C}$, the combined thermal and mechanical loads can reach $80 \%$ of the bearing capacity of the pile in compression, which would not be acceptable in design. Besides, the stress state conditions could worsen in the long term, highlighting the importance of proper structural analysis in the design phase of the pile heat exchangers.

Future attempts should account for more complex phenomena (pile-soil friction, thermo-mechanical constitutive laws of soils, pile group effects, etc.). Besides, the thermal influence between neighboring piles, the effect of the natural temperature variations of the soil and the impact of the building on top of the geothermal reservoir domain should be emphasized as they will affect the amount of usable thermal energy in the long-term.

\section{ACKNOWLEDGMENTS}

We kindly thank the following financial partners: Centrum Pæle A/S, INSERO Horsens and Innovationsfonden Denmark. We express our deep gratitude to Rosborg Gymnasium \& HF for facilitating access to their installations, to Víctor Marcos Mesón for his advice and the two anonymous reviewers for their comments. 


\section{REFERENCES}

Abdelaziz, S. L., Olgun, C. G. \& Martin Ii, J. R., 2015. Equivalent energy wave for long-term analysis of ground coupled heat exchangers. Geothermics, 53, 67-84.

Alberdi-Pagola, M., Jensen, R. L. \& Poulsen, S. E., 2016. A performance case study of energy pile foundation at Rosborg Gymnasium (Denmark). 12th REHVA World Congress Clima2016, 22-25 May 2016 Aalborg, Denmark. Department of Civil Engineering, Aalborg University, p. 10.

Amatya, B. L., Soga, K., Bourne-Webb, P. J., Amis, T. \& Laloui, L., 2012. Thermo-mechanical behaviour of energy piles. Geotechnique, 62, 503-519.

Bandos, T. V., Campos-Celador, Á., López-González, L. M. \& Sala-Lizarraga, J. M., 2014. Finite cylinder-source model for energy pile heat exchangers: Effects of thermal storage and vertical temperature variations. Energy, 78, 639-648.

Bourne-Webb, P. J., Amatya, B., Soga, K., Amis, T., Davidson, C. \& Payne, P., 2009. Energy pile test at lambeth college, London: Geotechnical and thermodynamic aspects of pile response to heat cycles. Geotechnique, 59, 237-248.

Brandl, H., 2006. Energy foundations and other thermo-active ground structures. Geotechnique, 56, 81-122.

Cecinato, F. \& Loveridge, F. A., 2015. Influences on the thermal efficiency of energy piles. Energy, 82, 1021-1033.

Comsol Multiphysics, 2015. COMSOL Multiphysics version 5.1: user's guide. In: COMSOL (ed.). Burlington.

Danish Energy Agency, 2012. Energy Policy in Denmark. Solid Media Solutions ed. Amaliegade 44, 1256 Copenhagen K, Denmark: Danish Energy Agency.

Dansk Geoteknik A/S, 1973. Geoteknisk rapport. Grundundersogelser for Amtsgymnasium i Vejle, Vestre Engvej, Vejle.

Di Donna, A., 2014. Thermo-mechanical aspects of energy piles. PhD Thesis, École polytechnique fédérale de Lausanne EPFL.

DS/EN 1997-1/AC, 2010. Eurocode 7: Geotechnical design - Part 1: General rules. Dansk Standard.

Geotechdata.Info., 2013. Soil elastic Young's modulus [Online]. Available: http://www.geotechdata.info/parameter/soilyoung's-modulus.html.

GSHP Association, 2012. Thermal Pile: Design, Installation \& Materials Standards. National Energy Centre, Davy Avenue, Knowlhill, Milton Keynes: Ground Source Heat Pump Association.

Hassani Nezhad Gashti, E., Malaska, M. \& Kujala, K., 2014. Evaluation of thermo-mechanical behaviour of composite energy piles during heating/cooling operations. Engineering Structures, 75, 363-373.

Knellwolf, C., Peron, H. \& Laloui, L., 2011. Geotechnical analysis of heat exchanger piles. Journal of Geotechnical and Geoenvironmental Engineering, 137, 890-902.

Laloui, L. \& Di Donna, A., 2011. Understanding the behaviour of energy geo-structures. Proceedings of the Institution of Civil Engineers-Civil Engineering, 2011. Thomas Telford Ltd, 184-191.

Laloui, L. \& Di Donna, A., 2013. Energy Geostructures: Innovation in Underground Engineering, John Wiley \& Sons, Inc.

Laloui, L., Nuth, M. \& Vulliet, L., 2006. Experimental and numerical investigations of the behaviour of a heat exchanger pile. International Journal for Numerical and Analytical Methods in Geomechanics, 30, 763-781.

Loveridge, F., 2012. The thermal performance of foundation piles used as heat exchangers in ground energy systems. $\mathrm{PhD} \mathrm{Thesis,}$ University of Southampton.

Loveridge, F. \& Powrie, W., 2013. Temperature response functions (G-functions) for single pile beat exchangers. Energy, 57, 554-564.

Mimouni, T., 2014. Thermomechanical Characterization of Energy Geostructures with Emphasis on Energy Piles. PhD Thesis, École polytechnique fédérale de Lausanne EPFL.

Mimouni, T. \& Laloui, L., 2014. Towards a secure basis for the design of geothermal piles. Acta Geotechnica, 9, 355-366.

Neville, A. M., 1995. Properties of concrete, Wiley.

NHBC Foundation, 2010. Efficient design of piled foundations for low-rise housing, design guide.

Olgun, C. G., Ozudogru, T. Y. \& Arson, C., 2014. Thermo-mechanical radial expansion of heat exchanger piles and possible effects on contact pressures at pile-soil interface.

Pahud, D. \& Hubbuch, M., 2007. Measured thermal performances of the energy pile system of the Dock Midfield at Zürich Airport. Proceedings European geothermal congress, 2007.

Park, H., Lee, S.-R., Yoon, S. \& Choi, J.-C., 2013. Evaluation of thermal response and performance of PHC energy pile: Field experiments and numerical simulation. Applied Energy, 103, 12-24. 
SIA, 2005. Utilisation de la chaleur du sol par des ouvrages de fondation et de soutènement en béton: guide pour la coneption, la réalisation et la maintenance, SIA, Société suisse des ingénieurs et des architectes.

Suguang, X., Suleiman, M. T. \& McCartney, J. S., 2014. Shear Behavior of Silty Soil and Soil-Structure Interface under Temperature Effects. Geo-Congress 2014. Atlanta, Georgia, USA: American Society of Civil Engineers.

Suryatriyastuti, M. E., Mroueh, H. \& Burlon, S., 2012. Understanding the temperature-induced mechanical behaviour of energy pile foundations. Renewable and Sustainable Energy Reviews, 16, 3344-3354.

VDI, 2001. VDI 4640 Thermal Use of the Underground. Part 3: Utilization of the Subsurface for Thermal Purposes. Underground Thermal Energy Storage. Berlin: VDI-Gessellschaft Energie und Umwelt (GEU).

VDI, 2010. VDI 4640 Thermal Use of the Underground. Part 1: Fundamentals, approvals, environmental aspect. Berlin: VDIGessellschaft Energie und Umwelt (GEU).

Xiao, J., Luo, Z., Martin Ii, J. R., Gong, W. \& Wang, L., 2016. Probabilistic geotechnical analysis of energy piles in granular soils. Engineering Geology, 209, 119-127. 